\title{
Critical Failure Analysis of Superheater Tubes of Coal-Based Boiler
}

\author{
Gagan Kumar Gupta* - Somnath Chattopadhyaya \\ ${ }^{1}$ Indian Institute of Technology (Indian School of Mines), Department of Mechanical Engineering, India
}

\begin{abstract}
This paper highlights a methodology for failure investigation of superheater tubes made of the material T-22 of a coal-based boiler. The process includes visual observation, the identification of sampling locations, the determination of the bulk chemical composition of the base alloy, microstructural investigation using optical microscopy, the exploration of finer structural details using a scanning electron microscope (SEM), the evaluation of hardness over samples obtained from different locations, the fractographic analysis of different failed locations, the $X$-ray diffraction (XRD) study of corrosion products adhered to inner surfaces, and the determination of the nature of the failure. Within a span of four months, three successive failures of superheater tubes were reported. The tubes were observed to have undergone significant wall thinning. Microscopic examinations using SEM on the failed region and a region some distance away on the as-received tubes were conducted in order to determine the failure mechanism. Layer-wise oxidation corrosion (exfoliation) in the inner surface was observed. Apart from major cracking, a number of nearly straight line crackings were observed in the longitudinal direction of both tubes. Close to cracking/bulging, void formation/de-cohesion of grain boundary indicated creep deformation under service exploitation. The failure mechanism was identified to be a result of excessive oxidation corrosion along the inside wall to reduce thickness, the spheroidization of alloy carbides and the coarsening of precipitate as well as creep void formation along grain boundary leading to inter-granular cracking with material flow near regions covered with thick scales. Moreover, there was a drastic reduction in bulk hardness of alloy and finally 'thin lip fish mouth' fractures.
\end{abstract}

Keywords: coal based boiler, corrosion, creep, fractographic analysis, SEM, superheater tube

Highlights

- Bulk chemical composition of base alloy has been determined.

- Optical microscopy has been applied for microstructural investigation.

- $\quad$ Details of finer structural have been explored by applying scanning electron microscope (SEM).

- Hardness of samples obtained from different locations of failed tubes has been evaluated.

- Fractographic \& X-ray diffraction XRD analysis has been performed at different failure locations.

- Nature/type of failure to highlight the cause of failure ae has been examined.

\section{INTRODUCTION}

A boiler is a vital element in power plants with regards to running cost and performance. A boiler generates steam via the optimized combustion of fuels (coal, gas \& oil, etc.). It consists of several components of rotary equipment and pressure parts. The efficient and trouble-free operation of a boiler is difficult to maintain because the characteristics of input fuel vary over time. Deteriorated performance and repetitive failures of pressure parts of boiler is a very common issue. One of the critical components of pressure parts is the superheater, the failure of which leads to the forced outage of the working of a boiler, resulting in huge losses. A superheater is basically a heat exchanger in which heat is transferred from furnace gas to steam. Improper heat transfer between steam and furnace gas creates problems of localized heating. Uneven heat transfer is a result of non-uniform gas flow or non-uniform steam distribution in the superheater. Significant causes of failure in superheaters are localized prolonged heating, creep damage, thermal fatigue, excessive thermal stresses, water and fireside corrosion, erosion, etc. General modes of failures observed in superheaters are wall thinning, reduced thickness, fish-mouth opening type bursting, creep cracks on tube surfaces and puncturing. Tube failure in the superheater is sufficiently hazardous to lead to the forced evacuation of the whole plant. Therefore, it is important to take remedial actions to prevent technical as well as economic losses. It is highly necessary not only to critically identify areas of failures but also to critically determine the root cause of failures. Prolonged localized heating, which is considered a root cause of tube failures, is a result of improper operating procedures. Concentrated gas flow pattern over superheater and non-uniform steam distribution overheats localized portions of tubes. Proper distribution of furnace gas among the entire superheater tubes and uniform steam flow in each tube are advocated for the trouble-free operation of superheaters. A pictorial view of a boiler is presented in Fig. 1 with location of superheater. Dennies [1], Wulpi [2] and Brooks and Choudhury [3] has presented 
guidelines and methods of failure analysis. Graham [4] and Ryder et al. [5] have described strategies and general practices for conducting failure analysis. Vander Voort [6] has presented failure analysis practices. Port and Herro [7] have suggested a reference guide for boiler failure analysis. Approximately 35 $\%$ of common failures in boilers are caused by long term overheating (creep) in superheater, reheaters, and wall tubes as per Rahmana et al. [8] and $\mathrm{Xu}$ et al. [9]. Manufacturing properties of materials and surface roughness have also been described as factors influencing the running conditions as per Krolczyk et al. [10] and Nieslony et al. [11]. Krolczyk and Legutko [12] have described the experimental analysis of surface roughness of duplex stainless steel. Jones [13] also reported the failure of four internally pressurized tubes involving a superheater that was failed by creep. Srikanth et al. [14] reported of failures of boiler tubes due to fireside corrosion in a waste heat recovery boiler utilizing exhaust gas. High corrosion propensity and consequent failures in the low-temperature sections of the boiler were found to be directly related to the formation of hydrated ferric sulphate in these regions. Chaudhuri [15] analysed tube failure and concluded that the failure takes place due to short-term overheating in the final superheater tubes. It is also reported that the non-failed re-heater tubes exhibit higher tensile properties than that of platen superheater tubes. Ranjbar [16] analysed the tube failure by chemical analysis of boiler cold and hot re-heater tubes. It was concluded that the improper maintenance and feed water quality/chemistry are the main causes of such failures. These observations have led to the development of various types of corrosion mechanisms.

Ahmad et al. [17] established excessive hoop stresses to be the cause of failure in a super alloy Inconel-800 superheater tube. The possibility of creep damage was checked using Larson-Miller parameter related to primary superheater tubes of a power plant by Ahmad et al. [18].Begum et al. [19] made an analysis of end crack in boiler tube. Rao and Sankara Narayanan [20] and Hanke [21] investigated causes of failure in boiler bank tubes and water wall tubes, respectively. Abbasfard et al. [22] also made a case study of failed superheater tubes of a waste heat boiler. Othman et al. [23] and Purbolaksono [24] have identified the failure of superheater tubes by performing finite element method (FEM) and by using an empirical formula in addition to visual inspections and metallurgical examinations. Botha and Hindley [25] have described the modelling methodology for boiler tube failure. Ahmad et al. [26] discussed the failure investigation of the rear water wall tube of a boiler using a method of calculating the hoop stress. It must be kept in mind that a failure of a tube is generally a sign of another problem, and it needs complete evaluations and investigations. Begum et al. [27] also conducted analysis to find failed boiler tube due to creep damage and optimization of operating conditions.

Kumarand Sapra [28] and Luo and Zhang [29] discussed the leakage failure analysis of boiler tubes in a power plant. Hasseand Hanke [30] concentrated on the analysis of economiser tube failure. Šeruga et al. [31] and Saha and Shukla [32] have developed a particular methodology for the investigation of

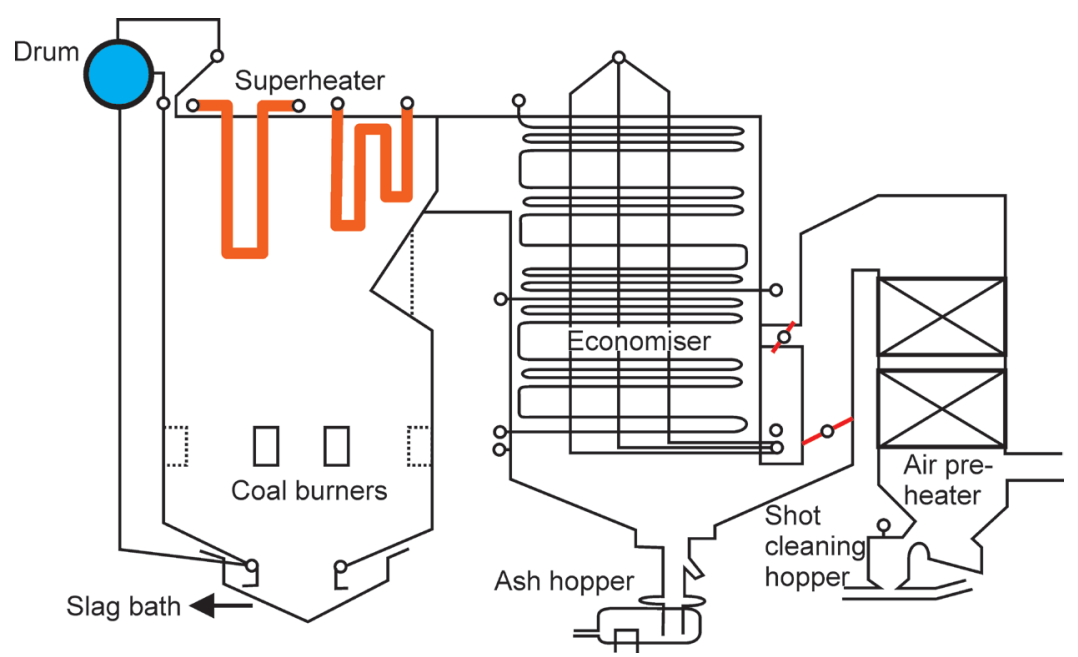

Fig. 1. Typical Boiler (OPG 260 TPH) in which failure of superheater tubes observed 
failed superheater tube subjected to either long service life or short service life by using modelling and several failure analysis methods. Shokouhmand [33] has described the failure analysis retrofitting of superheater tubes in utility boilers. Movahedi-Rad et al. [34] and Saha et al. [35] have described the failure analysis of superheater tubes. The failure analysis of boiler tubes and boiler re-heater tubes due to fatigue has also been conducted by $\mathrm{Hu}$ et al. [36]. Javidi et al. [37] has described the failure analysis of steel piping in a power plant. Liang et al. [38] has employed SEM and EDS for investigating overheating of the final super-heater in a $660 \mathrm{MW}$ power plant. Bettge et al. [39] has investigated the breakdown of a heat recovery steam generator during the initial operation run. Duda et al. [40] has measured hardness and tube thickness for a study of failed superheater tubes.

The present study has developed a generalized methodology for investigation of failed superheater tubes by considering feasible influential factors with suggestions for remedial actions. The tube material of the superheater in the present investigation was Cr-Mo low alloy steel of polish specification 'Steel $10 \mathrm{H} 2 \mathrm{M}$ ' with the intended operating temperature of $540{ }^{\circ} \mathrm{C}$, applied continuously with steam pressure around 88 bar. The present methodology was applied on failed superheater tubes of boiler of Bokaro Power Supply Co. Ltd (A Joint Venture Company of SAIL \& DVC), Bokaro (India). This boiler was commissioned in 1988 and last overhauled in December 2014. The

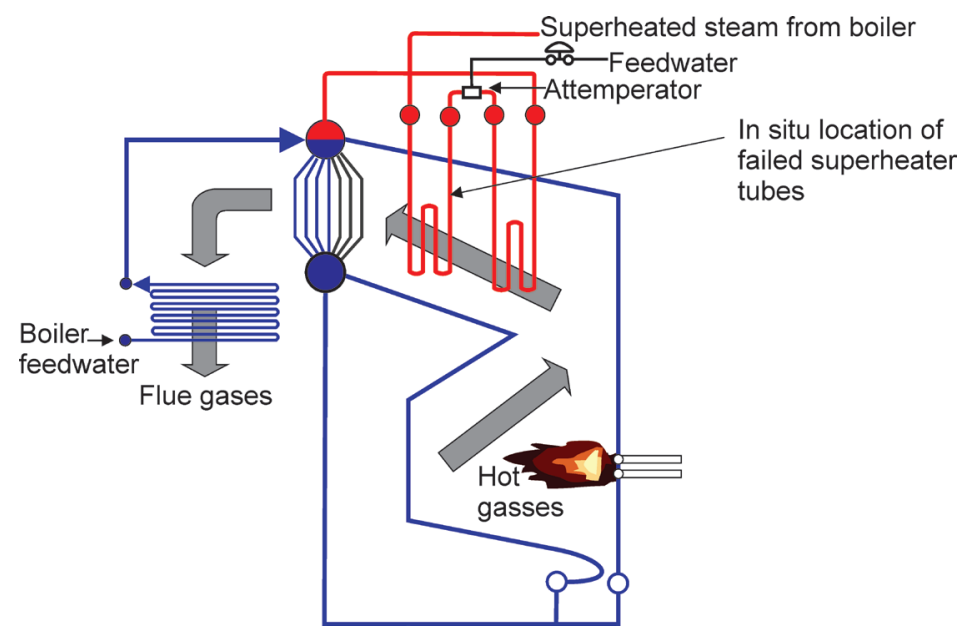

Fig.2. Arrangement of superheater tube with frequent failure zone in one panel

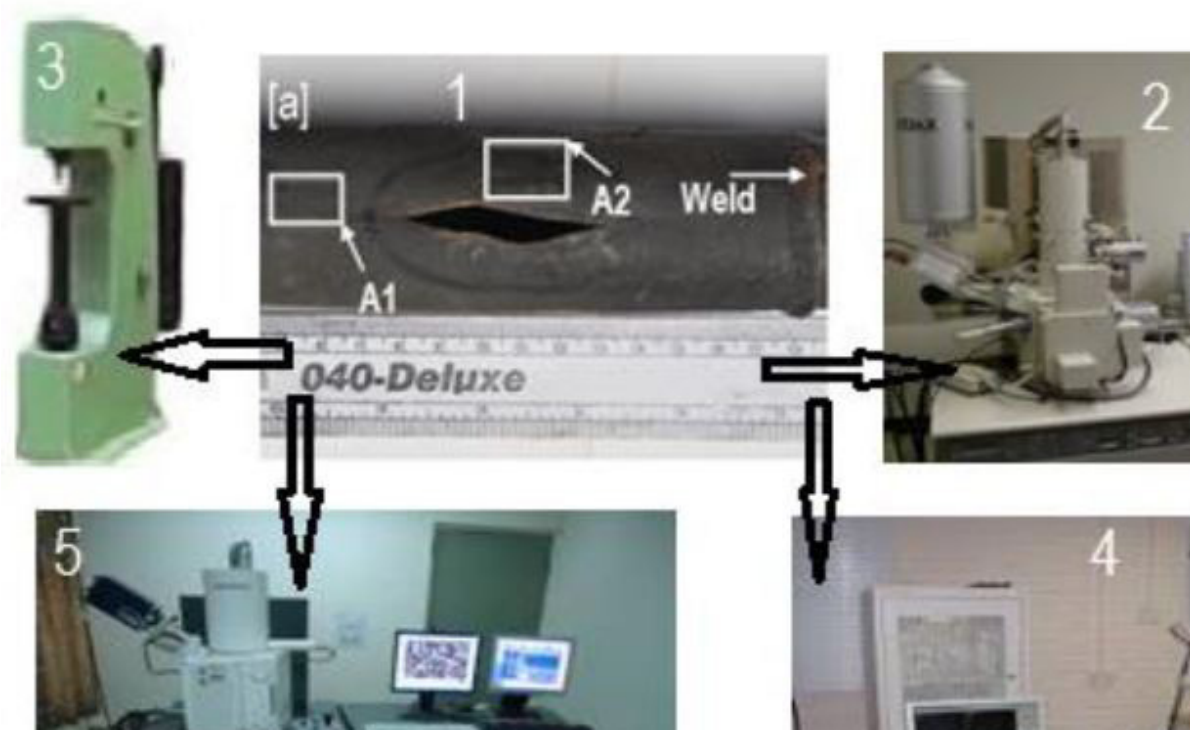

Fig. 3. Setup for methodology (1) collection of tubes, (2) EDS analysis, (3) hardness measurement, (4) SEM, (5) XRD analysis 
first failure of a superheater tube occurred on 2 April 2015. Subsequently, a second failure was reported on 12 April 2015, and third one took place in May to June 2015.

\section{DESCRIPTION OF SUPERHEATER}

The superheater is located in the radiation zone of a boiler where heat is transferred from flue gas to dry steam, flowing into superheater tubes. The temperature of flue gas in this zone is around $700{ }^{\circ} \mathrm{C}$ and the temperature of steam coming out of the superheater tubes (final superheated steam) is around $540 \pm 5$ ${ }^{\circ} \mathrm{C}$. Fig. 2 shows one panel of superheater tubes, and several numbers of such panels are arranged parallelly inside the boiler. It shows how the hot gases (flue gases) move inside the boiler. The superheater tubes are of varying thickness and material compositions with uniform outer diameters of $\varnothing 38 \mathrm{~mm}$.

\section{SUMMARIES OF FAILURES AND GENERALIZED METHODOLOGY}

The failed boiler tubes were made of Cr-Mo low alloy steel of polish specification 'Steel 10H2M'. The outer diameter of tube was $\varnothing 38 \mathrm{~mm}$ and thickness was $5.6 \mathrm{~mm}$. As per the onsite condition, some tubes were found punctured and some were deformed. Considering all aspects of operational and influential parameters, a generalized methodology was developed, which is illustrated as a graphical set up in Fig. 3 and as a flow diagram consisting of steps for testing of failed tubes in Fig. 4.

\section{EXPERIMENT RESULTS AND DISCUSSION}

The broken boiler tubes were visually observed to reveal the nature of the fracture. The tube was cut along the cross- section to examine the appearance of the inner wall after the incident of fracture. Samples were collected from different locations for investigation and the nomenclature is given in Table 1.

Samples A1 to A4 and B1 to B3 were considered for metallographic examination. They were mounted and polished with a conventional technique, etched with $3 \%$ Nital and examined by optical (Leica) and scanning electron (JEOL JSM 840A) microscopes. Fractured surfaces (near A2 and B2) were cleaned using dilute EDTA solution followed by kerosene oil and finally by ultrasonic cleaning with acetone. The samples were studied with SEM. Bulk composition of alloy was determined in inductive coupled plasma (ICP) and LECO using chips, obtained from cleaned

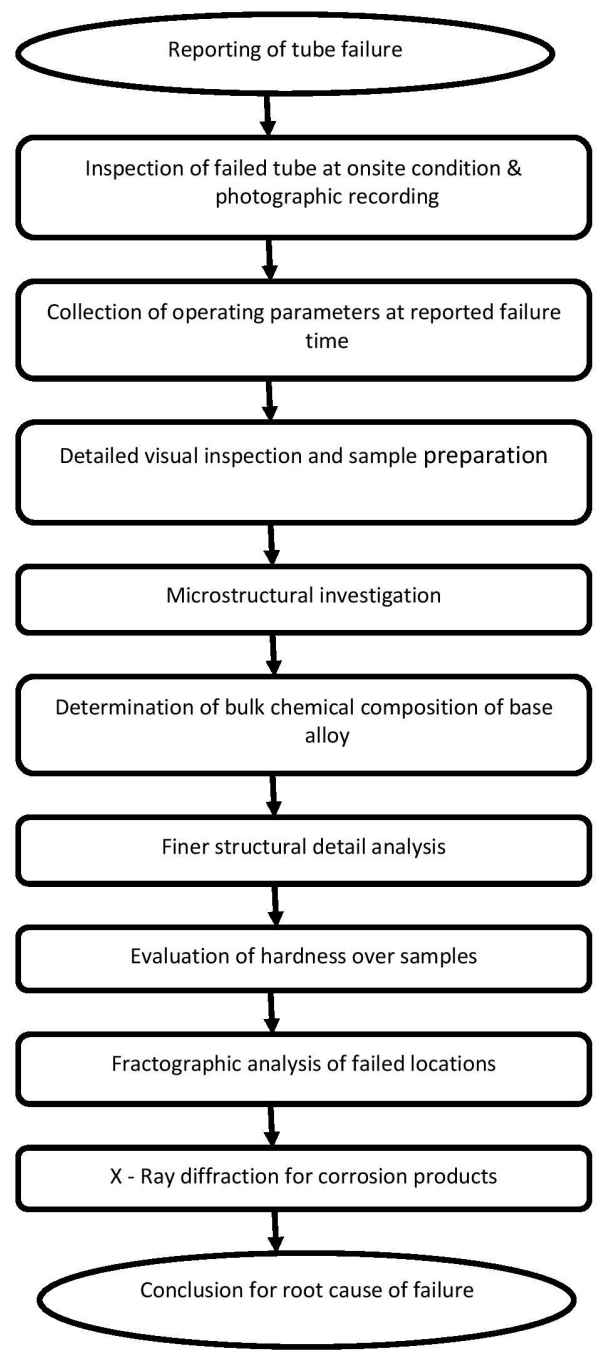

Fig. 4. Generalized methodology for failure analysis of tube

Table 1. Sampling location from fracture component and its nomenclature

\begin{tabular}{lll}
\hline Tube ID & Sample ID & Location \\
\hline Sample-A & Sample-A1 & Away from fracture \\
\cline { 2 - 3 } (P-14_T-6) & Sample-A2 & Sub-surface of fracture \\
\cline { 2 - 3 } & Sample-A3 & Near bulging \\
\cline { 2 - 3 } & Sample-A4 & Near Fracture (Across thickness) \\
\hline Sample-B & Sample-B1 & Away from fracture \\
\cline { 2 - 3 } (P-14_T-5) & Sample-B2 & Sub-surface of fracture \\
\cline { 2 - 3 } & Sample-B3 & Near Fracture (Across thickness) \\
\hline
\end{tabular}

surfaces. The chemical composition for major alloying elements was also examined by using energy dispersive spectroscopy to re-confirm the result of wet chemical analysis. Bulk hardness was evaluated 
near fracture and bulging zone in Brinell scale using steel ball as indenter. Certain amounts of adhered corrosion products were collected and examined with an X-ray diffraction technique to identify their nature. The investigation and corresponding inferences are described in the following sub-sections.

\subsection{Visual Examination}

Failed tubes were observed in reflected light with naked eyes (Figs. 5 and 6). Two tubes were designated as Sample-A (P-14_T-6) and Sample-B (P-14_T-5). Both tubes were supposed to have been exposed to temperatures of $540{ }^{\circ} \mathrm{C}$ with stress level at 100 bar during operation. Sample-A exhibited fish mouth cracking on one side (Fig. 5a) and bulging at the opposite side of the weld (Fig. 5b). The cut length of the tube was $\sim 400 \mathrm{~mm}$, and the wall thickness of non-deformed region was $\sim 5.80 \mathrm{~mm}$ with $\sim 36.8 \mathrm{~mm}$ outer diameter. From the weld seam, the distance of cracking was $\sim 40 \mathrm{~mm}$ and the total crack length was $\sim 50 \mathrm{~mm}$ with $\sim 6.7 \mathrm{~mm}$ maximum opening. Layerwise corrosion was observed near the open end of the crack, and the remaining wall thickness was reduced drastically $(\leq 1 \mathrm{~mm})$. Inner surface consisted of multiple crack formations along the longitudinal direction (Fig. 5c). However, crack formation was completely absent on the outer surface. The latter was blackened owing to thermal effect (Fig. 5a) and the inside surface was deep brown with numerous reddish spots (Fig. 5c). As pointed out already, bulging was observed on the lower half of the same tube. After bulging, the outer diameter became $\sim 42.0 \mathrm{~mm}$ with the distance of deformation at $\sim 12 \mathrm{~cm}$ from the weld
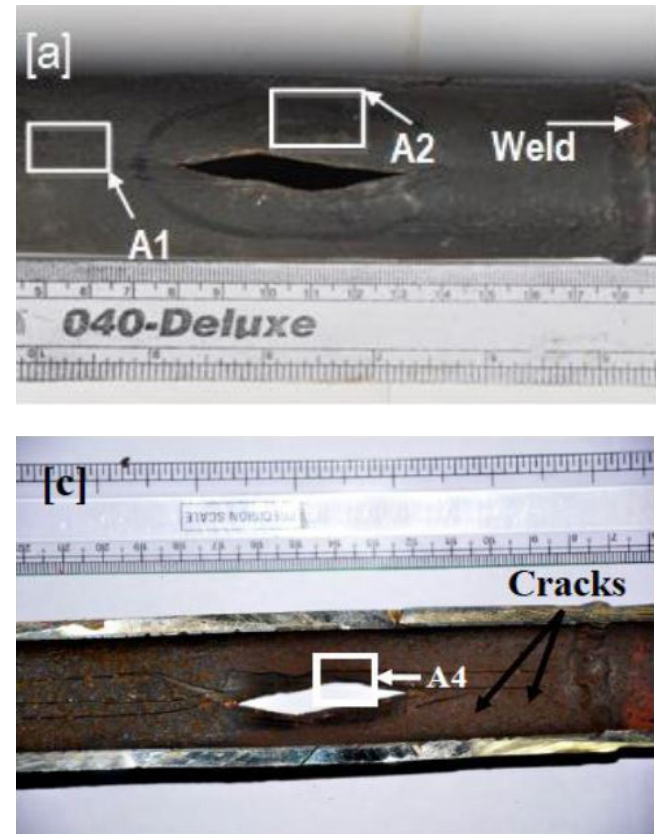
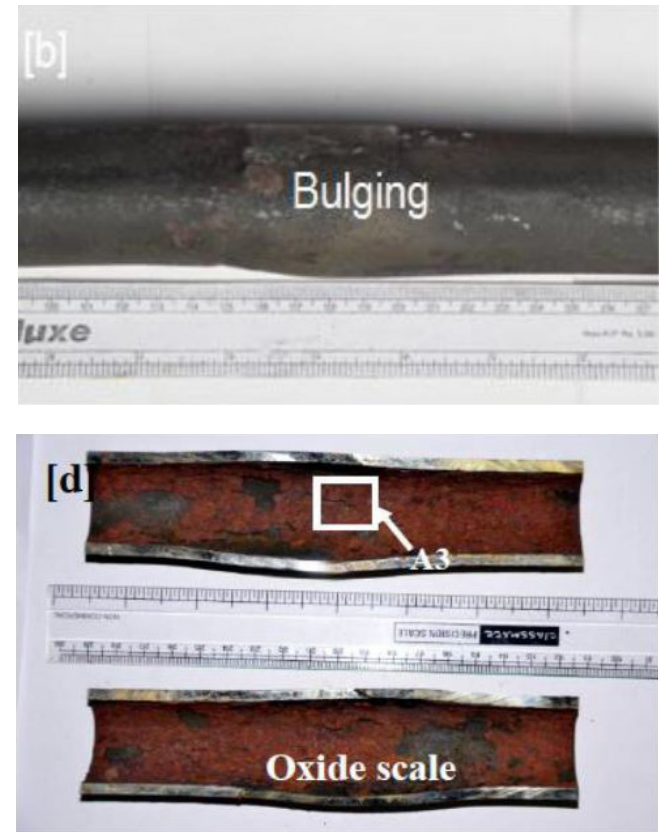

Fig. 5. Macro image and sampling location from damaged tube A: a) cracking over surface, b) bulged region, c) inner surface of tube, and d) inner surface of bulged region
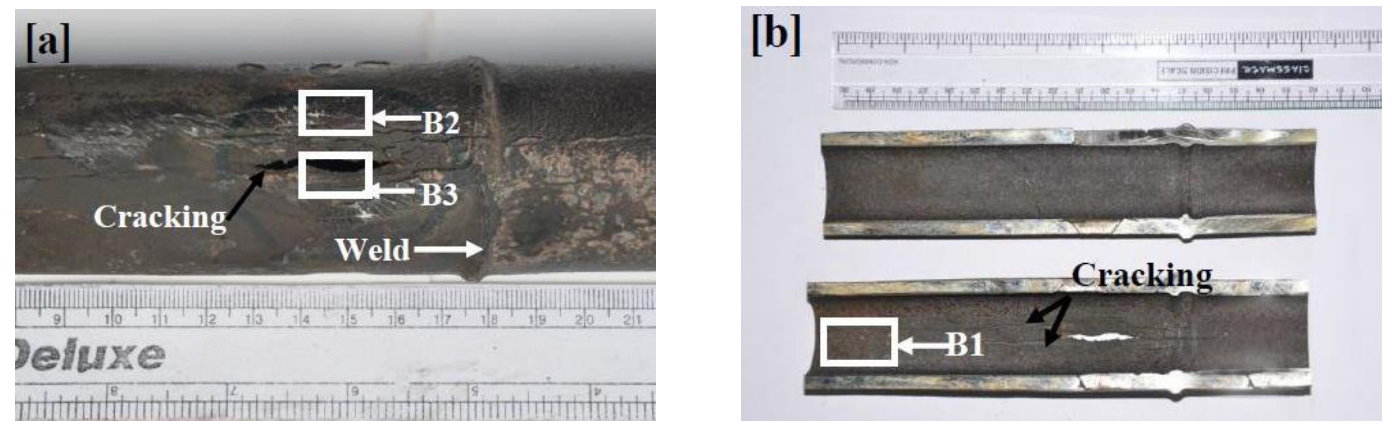

Fig. 6. Macro image and sampling location from damaged tube B: a) cracking over surface, and b) appearance of inner surface 
Table 2. Bulk chemical composition of component

\begin{tabular}{|c|c|c|c|c|c|c|c|c|c|}
\hline \multirow{2}{*}{ Alloy } & \multicolumn{9}{|c|}{ Element in wt\% } \\
\hline & C & $\mathrm{Si}$ & $\mathrm{Mn}$ & $\mathrm{Cr}$ & Mo & $S(\max )$ & $P(\max )$ & $\mathrm{Fe}$ & $\mathrm{Ni} / \mathrm{Cu}(\max )$ \\
\hline Steel 10H2M & 0.08 to 0.15 & 0.15 to 0.30 & 0.3 to 0.6 & 2.0 to 2.5 & 0.9 to 1.1 & 0.30 & 0.30 & bal & 0.30 \\
\hline Din 10CrMo9-10 & 0.08 to 0.14 & $0.5 \max$ & 0.4 to 0.8 & 2.0 to 2.5 & 0.9 to 1.1 & 0.01 & 0.02 & bal & 0.30 \\
\hline T22 & 0.05 to 0.15 & $0.5 \max$ & 0.3 to 0.6 & 1.9 to 2.6 & 0.87 to 1.13 & 0.025 & 0.025 & bal & $\mathrm{NI}$ \\
\hline EDS analysis of sample A & NA & 0.27 & 0.41 & 2.25 & 0.99 & NA & NA & bal & $\mathrm{N} / \mathrm{F}$ \\
\hline ICP + LECO analysis of A & 0.093 & 0.39 & 0.53 & 2.25 & 0.95 & 0.006 & 0.011 & bal & $0.05 / 0.016$ \\
\hline EDS analysis of sample B & NA & 0.32 & 0.47 & 2.10 & 1.03 & NA & NA & bal & $\mathrm{N} / \mathrm{F}$ \\
\hline ICP + LECO analysis of B & 0.108 & 0.39 & 0.54 & 2.26 & 0.95 & 0.006 & 0.011 & bal & $0.05 / 0.017$ \\
\hline
\end{tabular}

*NA - Not analysed, N/F - not found, NI- not indicated
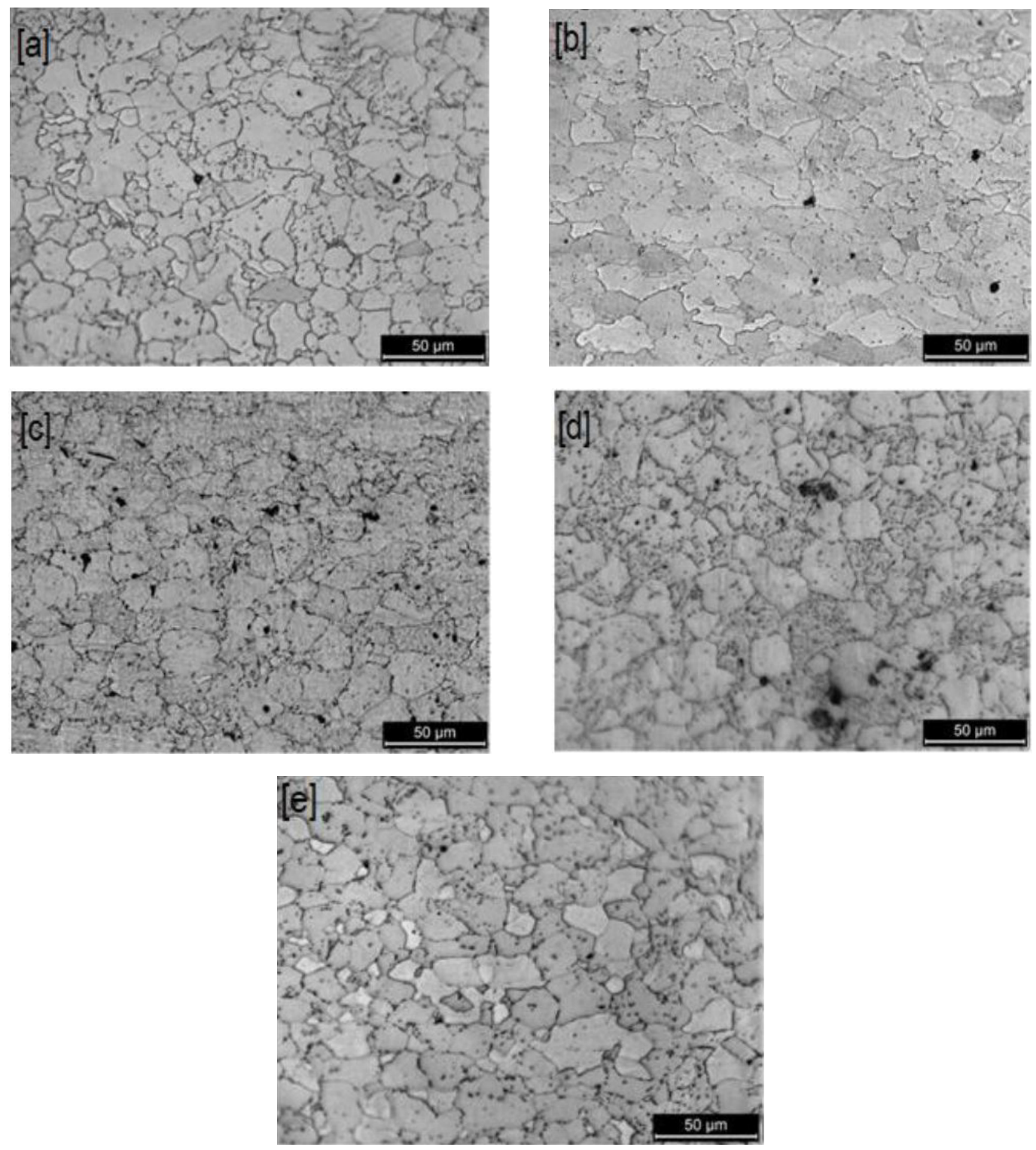

Fig. 7. Optical microstructure of transverse section of damaged tubes:

a) sample $A 1$, b) sample $A 2$, c) sample $A 3$, d) sample $B 1$ and e) sample B2; all samples exhibited ferrite matrices containing large voids, spheroidization\& coalescence of carbides preferably along the grain boundary 
seam. Thick scale $\left(42 \mathrm{mg} / \mathrm{cm}^{2}\right)$ of oxide products were loosely stuck to the inner surface near the bulging (Fig. 5d). No significant layer of oxide products was found on the outer surface.

Sample-B also contained fish mouth cracking on one part of the tube, and the other part exhibited no such degeneration. The total length of the cut portion of the tube was $\sim 250 \mathrm{~mm}$, wall thickness was $\sim 6.2 \mathrm{~mm}$ while the outer diameter was $\sim 39.0 \mathrm{~mm}$. A crack developed adjacent to the weld seam with a length of $\sim 30 \mathrm{~mm}$ and a maximum crack opening of $\sim 2.8 \mathrm{~mm}$. Both the inner and outer surface contained longitudinal cracking of variable length (Fig. 6). The interior of the tube was loosely covered with fine brown whiskers, which were generated from oxidation corrosion $\left(28 \mathrm{mg} / \mathrm{cm}^{2}\right)$ (Fig. 6b). However, no scale formation was observed on the outer surface of the tube. The fractured surface was dull in appearance and comprised a layered brown structure due to oxidation corrosion (Fig. 6a). Excessive thinning was found in the close vicinity of the failure. Thin lip fish mouth cracking with the presence of oxide scales at both the failed locations indicated two operating mechanisms of degeneration, i.e. oxidation corrosion followed by overload failure.

\subsection{Chemical Composition}

Details of the concentration of alloying elements have been collated in Table 2. The chemical composition of the bulk specimen refers to the polish composition of Steel 10H2M. The equivalent specification was close to DIN 10CrMo9-10 / T22. No remarkable variation can be observed in the chemical composition of the failed tubes. Therefore, damage owing to faulty chemistry of the alloy can be ruled out.

\subsection{Microstructural Examination}

The optical microstructures of the damaged components are shown in Fig. 7, which predominantly consists of polygonal ferrite. All parts of Fig. 7 showing the dark voids were observed close to the grain boundary. This is an indication of creep deformation. A few globular/elliptical/near-globular diffused shaded islands of variable size can also be found. These are perhaps globular carbide present due to spheroidization under high-temperature exposure (over the operating temperature i.e. $\sim 540{ }^{\circ} \mathrm{C}$ ). With respect to the non-deformed grain shape (Figs. 7a and d), the grain shape near the fracture (Figs. $7 \mathrm{~b}$ and e) exhibits slight increment in aspect ratio with a loss of angularity. This is an indication of material flow under stress at elevated temperature leading to further wall thinning after the initial reduction of thickness due to exfoliation.
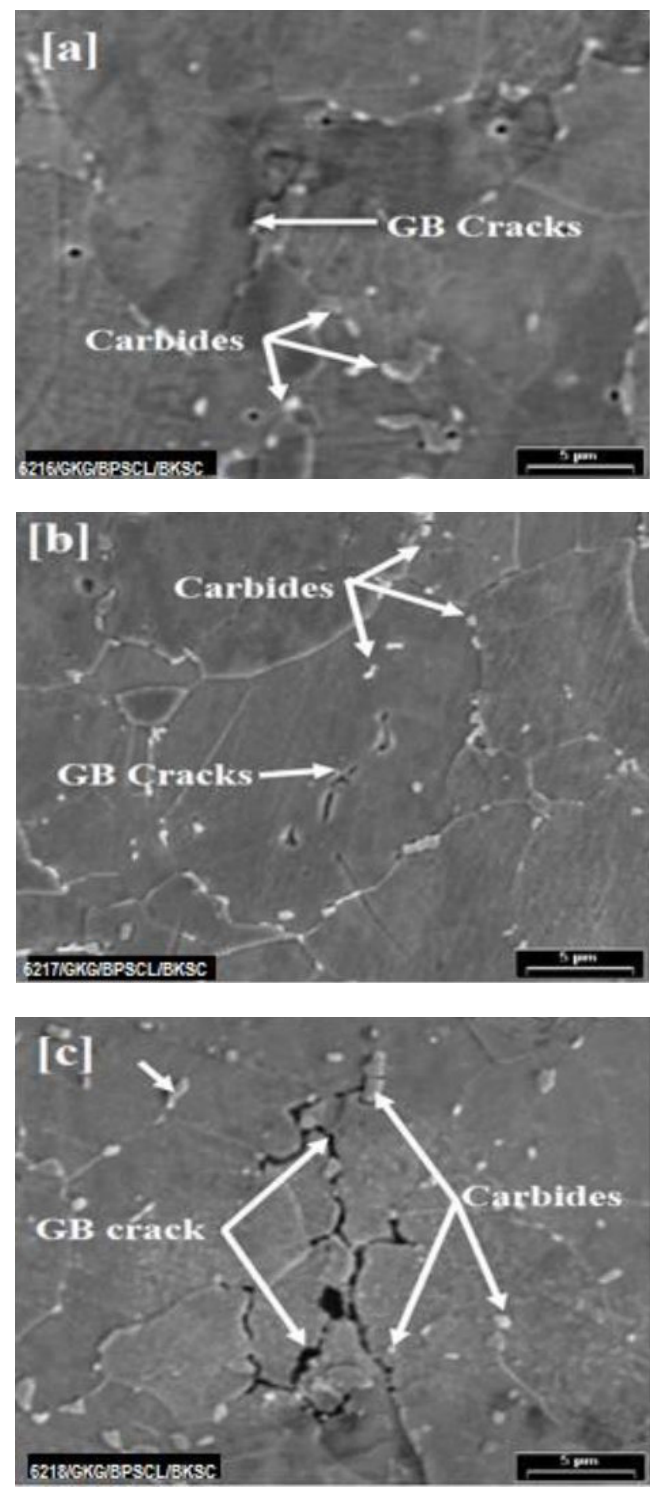

Fig. 8. SEM micrographs of transverse section of damaged tubes: a) sample $A 2$, b) sample $A 3$, and c) sample B2; g.b. voids / cracks and alloy carbides were visible along grain boundary

SEM micrographs confirmed the inferences drawn from optical imaging (Fig. 8). Along the grain boundary, bright islands indicated the spheroidization of carbides (indicated by arrows). Fig. 8 shows the void coalescence along the grain boundary, resulting in crack formation. The region close to bulging also revealed that interconnected voids that were generated during service exploitation. These voids area signature of creep damage developing at elevated temperature 

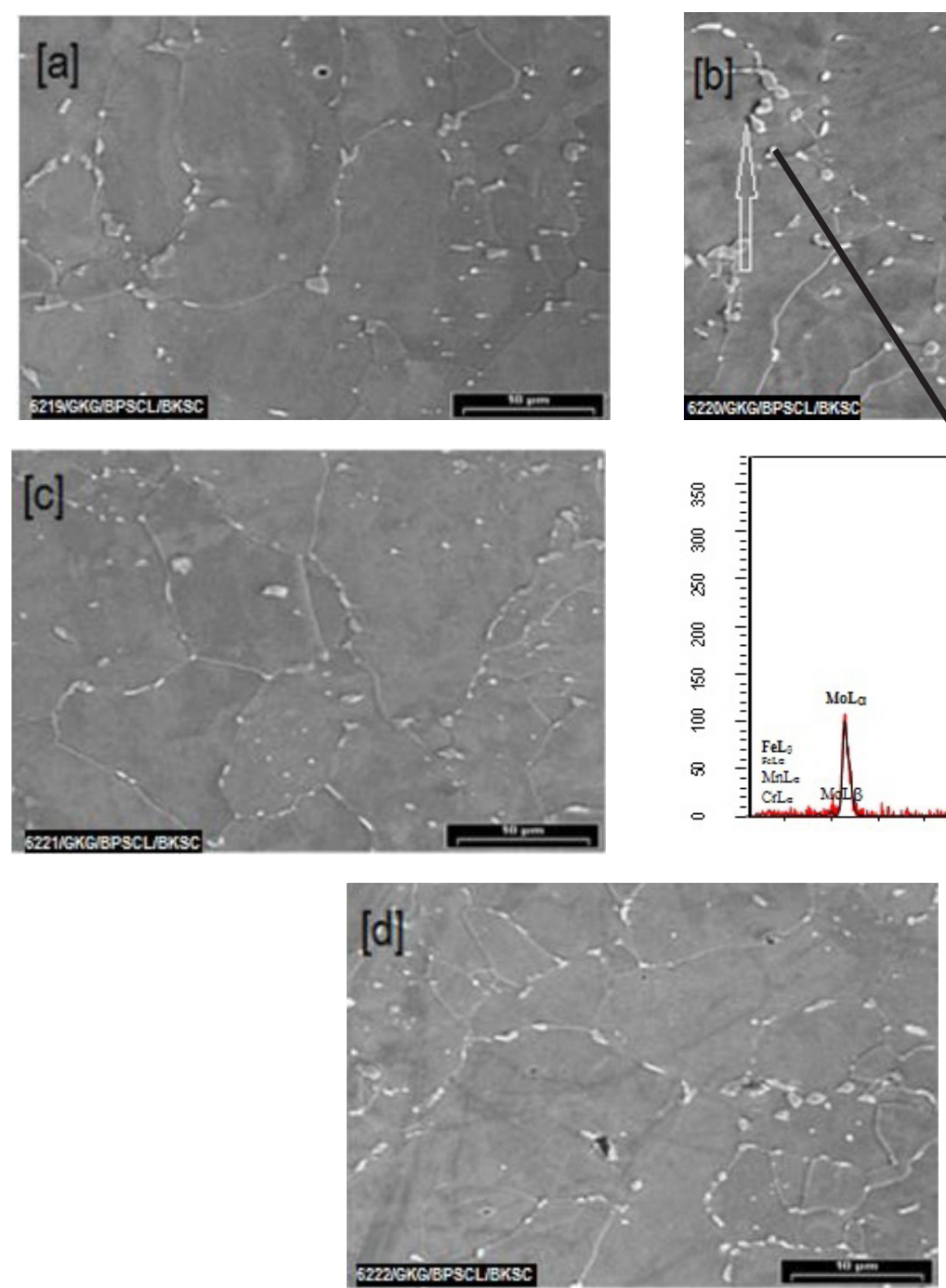

Fig. 9. SEM micrographs across inner to outer region of damaged tubes: a) inner - sample A4, b) outer - sample A4 with EDS spectrum from precipitate as shown in Figure 10b with quantification indicating Cr-Mo rich alloy carbide, c) inner - sample B3, and d) outer - sample B3

under stress. The rise of local temperature beyond the designated/recommended limit over time, led to grain boundary sliding. The sliding generated decohesion/voids at the boundary. Overtime, the voids grew and became inter connected. This weakened the grain boundary strength, ultimately reducing the load bearing capability of the component. Hence, severe spheroidization of carbide and void generation are indications of local temperature rise. Therefore, temperature rises at high-stress levels cause three phenomena i.e. carbide spheroidization, creep damage to create voids, and material flow resulting in wall thinning.

SEM investigation was also carried out from inner to the outer surface to find pre-dominant
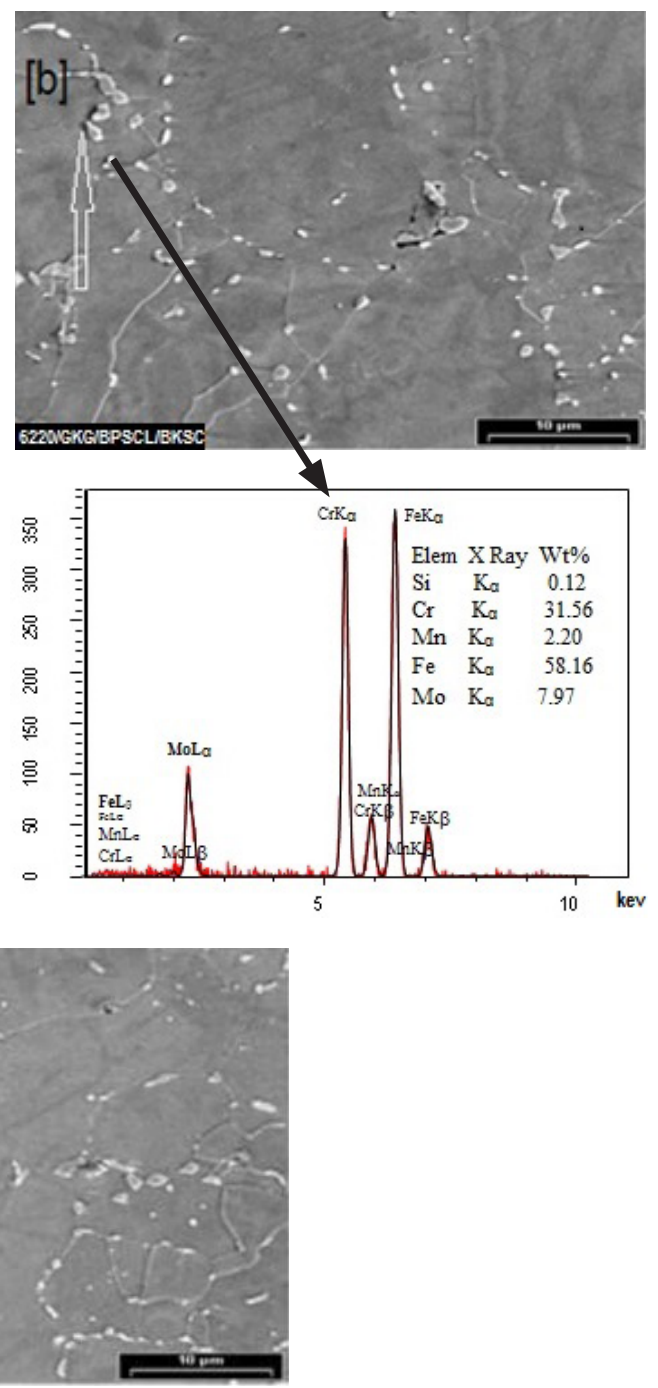
on the basis of the material hardness of $\sim 200 \mathrm{BHN}$ as indicated in published literature/standards for this grade of Cr-Mo steel, the hardness was found to reduce drastically near the fracture, indicating materials softening during service. The bulged area exhibited slightly more hardness assuming that the damage might be slightly less in the fractured location during the same time span. With a longer time, the hardness of bulged area might reach the hardness level of the failure location.

Table 3. Bulk hardness of failed tubes at different location

\begin{tabular}{cccc}
\hline & Sample A2 & Sample B2 & Sample B3 \\
\hline Hardness (BHN) & $114 \pm 1.5$ & $114 \pm 0.5$ & $126 \pm 1$
\end{tabular}

\subsection{X-Ray Diffraction Study}

X-ray diffraction analysis revealed the presence of different Fe-oxides and hydroxides as products of corrosion. The bulk composition of such deposits was also examined in EDS to qualitatively determine the constituents (Fig.10). Major peaks in illustration indicate the presence of iron and oxygen. Corrosion products mainly comprise iron oxide in association with small amounts of other chemical species of steel.

\subsection{Fractography}

SEM fractographs of both tubes are displayed in Fig. 12. Large micro-voids/dimples can be observed indicating softening of the tube material (Fig.11). The softening of the alloy was established with the reduction in bulk hardness (which is lower than 200 HB) as indicated in Table4. Ductile fracture signifies micro-void coalescence resulting in overload failure. For Sample A, the fractured surface is mostly covered with oxides, and it is difficult to explore specific features underneath, apart from the ductility failure
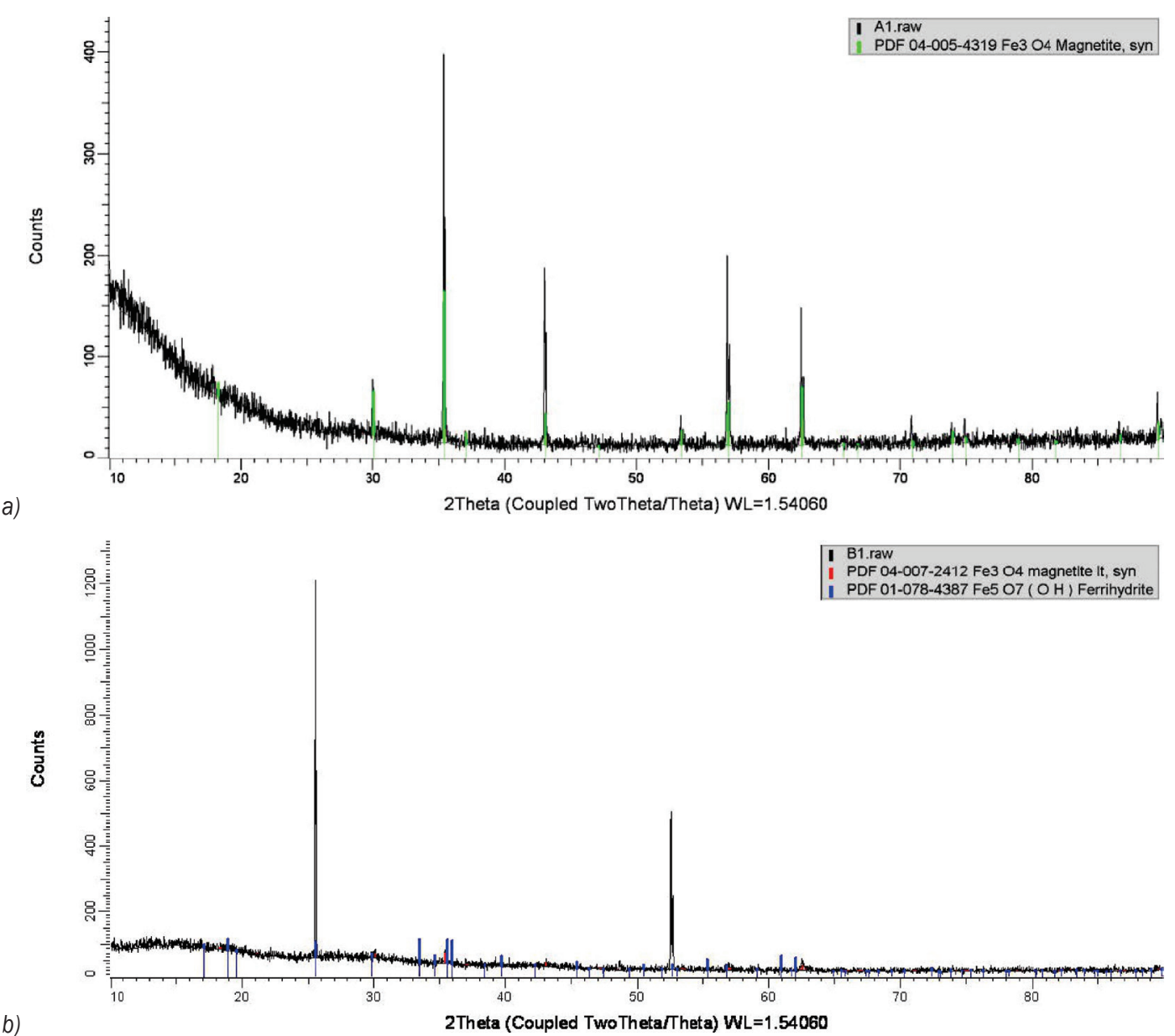

Fig. 10. X-ray characteristic spectrum from the deposits of oxidation corrosion; a) Tube - A, and b) Tube-B; corrosion products were mostly iron oxides and hydroxides of different grades 
(Fig. 11a). However, most of the area of the fractured surface indicated ductile dimple fracture (Fig. 11b).

In certain regions, a cracked thick skin of oxide layer can be found (Fig. 12a). In case of Sample B2, inter-granular failure can be observed (arrows in Fig. $12 \mathrm{~b})$ at localized regions. This inter-granular cracking originated from voids adjacent to the grain boundary due to creep deformation (Fig. 8). Thus, thin lip fish mouth openings of fractured surfaces on both tubes $\mathrm{A}$ and $\mathrm{B}$ is the signature of mixed mode failure. In such case, creep deformation is accompanied by wall thinning through necking. It reduces the strength of alloy, resulting in dimple rupture. If creep happens to be the only operating mechanism, then it turns into thick lip fish mouth failure as there would be no scope for material flow/deformation to reduce wall thickness.

\subsection{Evaluation of Hoop Stress}

In a straight tube, any force applied over circumference/cylindrical wall (a normal stress
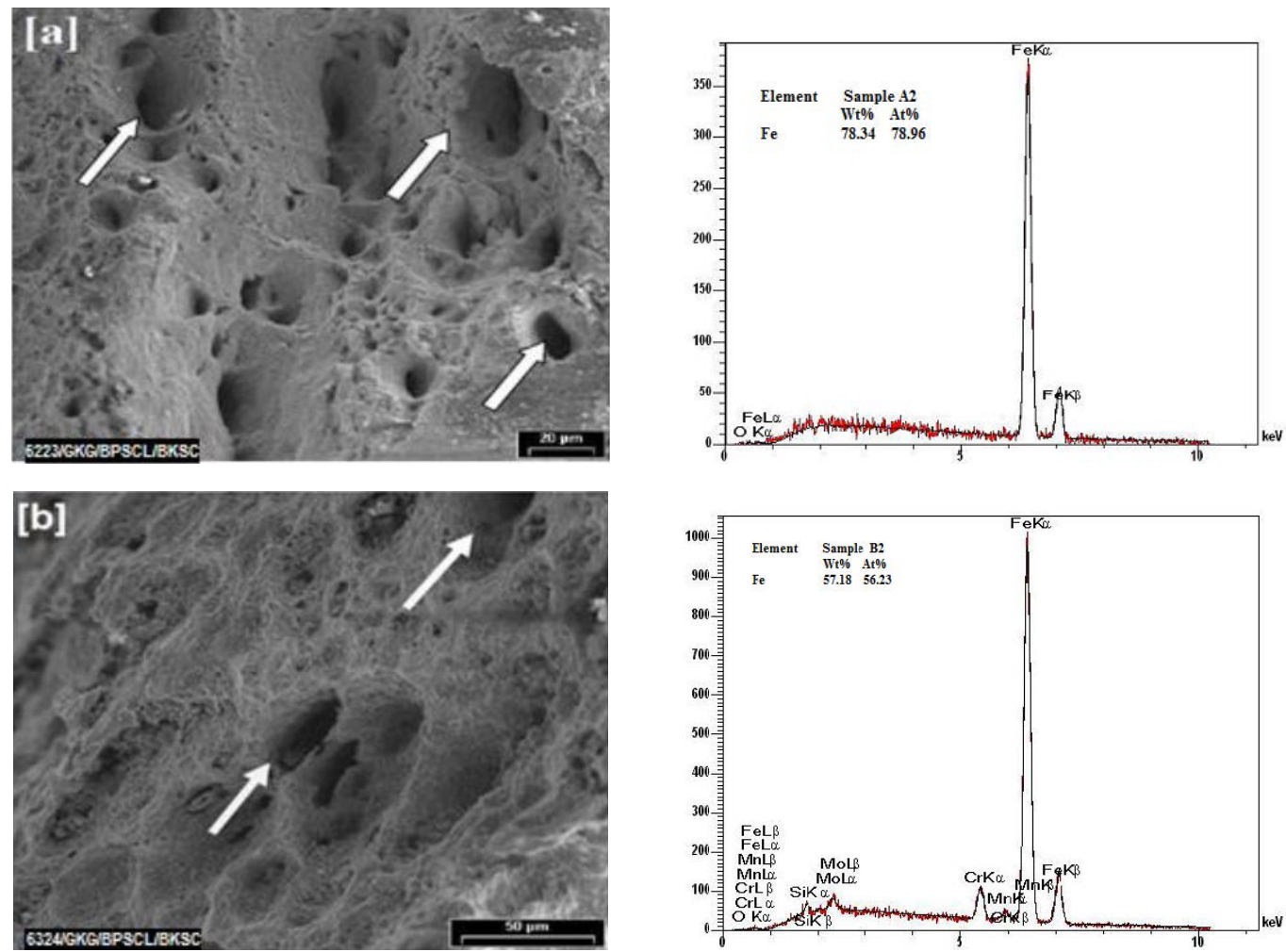

Fig. 11. SEM fractographs of damaged tubes near sample with qualitative EDS analysis of scales formed inside a) the sampleA2, and b) the sample $B 2$
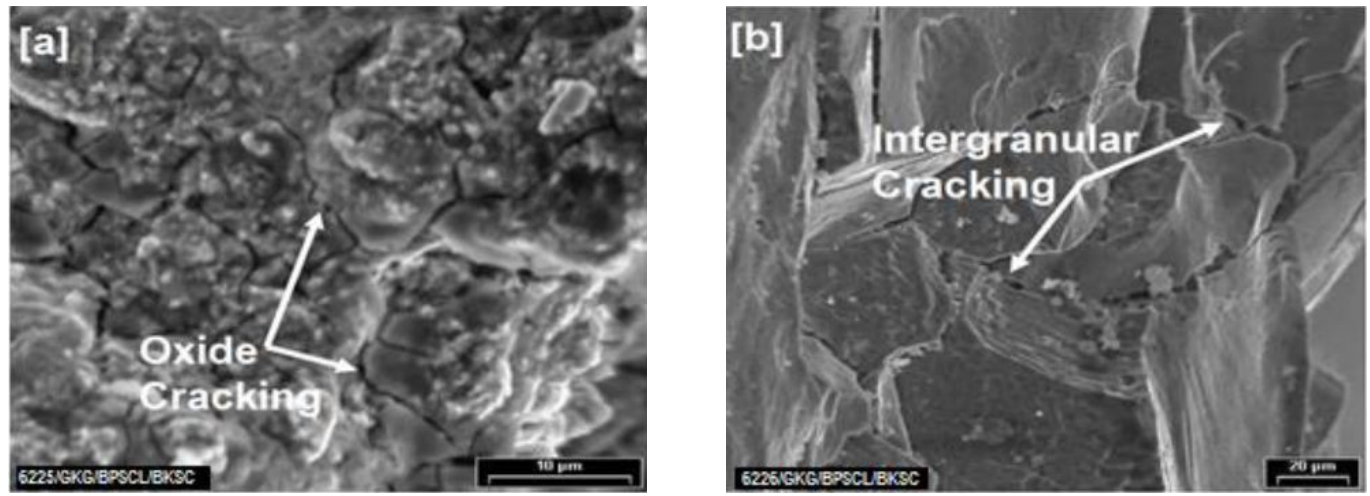

Fig. 12. SEM fractographs of Cracks near damaged tubes; a) near sample A2 and b) near sample B2 
along tangential/azimuth direction) is termed as circumferential stress or hoop stress. Hoop stress is tensile in nature. In case of thin-walled tube, it has been assumed that wall thickness becomes no more than one-tenth of its radius. This allows the wall to be considered as a surface and subsequently applying the Young-Laplace equation for assessing the hoop stress. The thickness of thin lip at burst area of sample A \& B is variable. The minimum thickness of thin lip is given in Table 4.

Table 4. Minimum thickness of thin lip at burst area

\begin{tabular}{ccc}
\hline \multirow{2}{*}{ Thickness $[\mathrm{mm}]$} & Sample A & Sample B \\
\cline { 2 - 3 } & 0.55 & 0.37 \\
\hline
\end{tabular}

Fracture is governed by hoop stress in the absence of other external loads, since it is the principal stress factor. One important point to note is that the greatest stress is generated inside tubes. Hence, cracks in tubes should theoretically develop from inside the tube. Yielding is governed by an equivalent stress that includes hoop stress and longitudinal or radial stress when present. Hoop stress is expressed as:

$$
\sigma=P \times d(2 t)^{-1}
$$

where, $P$ is the stress in $\mathrm{MPa}, d$ is the internal diameter of tube in $\mathrm{mm}$ and $t$ is the wall thickness in $\mathrm{mm}$. By considering the inside operating pressure of tube at 100 bar, the hoop stress in non-deformed and deformed regions of tubes $\mathrm{A}$ and $\mathrm{B}$ was calculated and given in Table 5. These values have been compared with room temperature tensile properties of annealed T22 alloy.

Table 5. Hoop stress distribution in failed tubes

\begin{tabular}{|c|c|c|c|c|}
\hline \multirow{2}{*}{ Sample ID } & \multicolumn{2}{|c|}{ Hoop stress $\sigma[\mathrm{MPa}]$} & \multirow{2}{*}{$\begin{array}{c}\mathrm{YS} \\
{[\mathrm{MPa}]}\end{array}$} & \multirow{2}{*}{$\begin{array}{c}\text { UTS } \\
{[\mathrm{MPa}]}\end{array}$} \\
\hline & Non-deformed & Deformed & & \\
\hline Sample-A & 21.3 & 224.7 & & \\
\hline Sample-B & 21.0 & 352.6 & & \\
\hline T22 alloy & & & 220.0 & 415.0 \\
\hline
\end{tabular}

From Table 5, it is evident that in comparison with non-deformed regions, the deformed region has undergone excessive normal stress during service exploitation due to oxidation corrosion-assisted wall thinning, which is greater than the yield strength of the tube material. Considering T22 alloy, this category of $\mathrm{Cr}-\mathrm{Mo}$ steel is able to retain its strength up to $\sim 520^{\circ} \mathrm{C}$ and then reduces drastically and may reach $\sim 30 \mathrm{MPa}\left(0.25\right.$ off-set yield) at $\sim 600^{\circ} \mathrm{C}$. Therefore, apart from oxide scales, local heating beyond operating temperature propels material flow and softens to further thin the tube wall. This thin wall is unable to withstand high hoop stress, and this fails due to overloading.

\section{CONCLUSIONS}

In the present study, the failure mechanism in superheater tubes has been investigated. Superheater tubes were made of Cr-Mo low alloy steel, the composition of which is close to the polish specification of 'Steel 10H2M'. Its equivalent specification is DIN 10CrMo910 / T22. The concentration of major chemical species of failed tubes was within the specified limit. Therefore, failure due to discrepancy in composition can be ruled out. As the received microstructure of steel consisted of polygonal fine grain, ferrite can be assumed to contain some amount of pearlite and complex alloy carbides. During service exposure, initially oxide scales were formed inside the tube. Thus, exfoliation inside the tube reduced the effective wall thickness. When the scale grew substantially, it hindered heat flow across the tube wall. Localized heating took place. Heating coarsened the carbides and propelled precipitation of new brittle phases along the grain boundary. At elevated temperatures, the grain boundary also lost its angularity. Moreover, due to internal deposits and partial choking, tubes are subjected to long-term overheating. The reason for long term overheating of the tube is the fact that tubes are subjected to temperatures so high that it causes their instantaneous bulging to a failure point. During this period, the outer of tubes surface develops bulging as well, resulting in elongated fissures along their axis. These two simultaneous phenomena, i.e. reduction of wall thickness of tube and its softening due to structural degeneration, come into play.

To summarize, the failure mechanism includes excessive oxidation corrosion inside the tube wall, reducing thickness, the spheroidization of alloy carbides, and the coarsening of precipitate along grain boundary. There is also loss of angularity and creep void formation along the grain boundary leading to inter-granular cracking with material flow near regions covered with thick scales. Further, there is a drastic reduction in bulk hardness (lower than 200 HB) of the tubes and, finally, thin lip fish mouth fracture develops at both the failed locations, leading to failure. 


\section{REFERENCES}

[1] Dennies, D.P. (2005). How to Organize a Failure Investigation. ASM International, Ohio.

[2] Wulpi, D.J. (2000). Techniques of failure analysis. Miller, B. (ed.) Understanding How Components Fail. ASM International, Ohio.

[3] Brooks, C.R, Choudhury, A. (1993). Metallurgical Failure Analysis. McGraw-Hill, New York.

[4] Graham, R. (2004). Strategies for failure analysis. ASM Advanced Materials \& Processes, vol. 172, no. 11, p. 45-50.

[5] Ryder, D.A., Davies, T.J., Brough, I., Hutchings, F.R. (1986). General practice in failure analysis. Failure analysis and prevention. Metals handbook, American Society for Metal, Ohio.

[6] Vander Voort, G.F. (2002). Conducting the Failure Examination Practice. ASM Handbook, ASM International, Ohio.

[7] Port, R.D., Herro, H.M. (1991). The NALCO Guide to Boiler Failure Analysis. Nalco Chemical Company, McGraw-Hill, New York.

[8] Rahmana, M. M., Purbolaksono, J., Ahmad, J. (2010). Root cause failure analysis of a division wall superheater tube of a coal-fired power station. Engineering Failure Analysis, vol. 17, no. 6, p. 1490-1494, D0l:10.1016/j.engfailanal.2010.05.005.

[9] Xu, L., Khan, J. A., Chen, Z. (2000). Thermal load deviation model for superheater and reheater of a utility boiler. Applied Thermal Engineering, vol. 20, no. 6, p. 545-558, D0l:10.1016/ S1359-4311(99)00049-6.

[10] Krolczyk, G., Legutko, S., Stoic, A. (2013). Influence of cutting parameters and conditions onto surface hardness of duplex stainless steel after turning process. Tehnički vjesnik Technical Gazette, vol. 6, no. 1, p. 1077-1080.

[11] Nieslony, P., Cichosz, P., Krolczyk, G.M., Legutko, S., Smyczek, D., Kolodziej, M. (2016). Experimental studies of the cutting force and surface morphology of explosively clad Ti-steel plates. Measurement, vol. 78, p. 129-137, D0I:10.1016/j. measurement.2015.10.005.

[12] Krolczyk, G.M., Legutko, S. (2014). Experimental analysis by measurement of surface roughness variations in turning process of duplex stainless steel. Metrology and Measurement Systems, vol. 21, no. 4, p. 759-770, D0l:10.2478/mms-20140060.

[13] Jones, D.R.H. (2004). Creep failures of overheated boiler, superheater and reformer tubes. Engineering Failure Analysis, vol. 11, no. 6, p. 873-893, D0l:10.1016/j. engfailanal.2004.03.001.

[14] Srikanth, S., Ravikumar, B., Das, S.K., Gopalakrishna, K., Nandakumar, K., Vijayan, P. (2003). Analysis of failures in boiler tubes due to fireside corrosion in a waste heat recovery boiler. Engineering Failure Analysis, vol. 10, no. 1, p. 59-66, DOI:10.1016/S1350-6307(02)00030-4.

[15] Chaudhuri, S. (2006). Some aspects of metallurgical assessment of boiler tubes-Basic principles and case studies. Journal of Material Science and Engineering: A, vol. 432, no. 1-2, p. 90-99, D0l:10.1016/S1350-6307(02)00030-4.

[16] Ranjbar, K. (2007). Failure analysis of boiler cold and hot reheater tubes. Engineering Failure Analysis, vol. 14, no. 4, p. 620-625, D0I:10.1016/j.engfailanal.2006.03.007.
[17] Ahmad, A., Purbolaksono, J., Beng, L. C. (2010). Failure analysis on high temperature superheater Inconel ${ }^{\circledR} 800$ tube. Engineering Failure Analysis, vol. 17, no. 1, p. 328-333, Dol:10.1016/j.engfailanal.2009.06.013.

[18] Ahmad, J., Rahman, M., Zuhairi, M.H.A., Ramesh, S., Hassan, M.A., Purbolaksono, J. (2012). High operating steam pressure and localized overheating of a primary super heater tube. Engineering Failure Analysis, vol. 26, p. 344-348, D0l:10.1016/j.engfailanal.2012.08.012.

[19] Begum, S., Karim, A.N.M., Nainar, M.A.M., Sevah, S. (2012). Analysis of end crack in boiler tube. Advanced Materials Research, vol. 576, p. 749-752, D0l:10.4028/www.scientific. net/AMR.576.749.

[20] Ananda Rao, M., Sankara Narayanan, T.S.N. (2012). Failure investigation of a boiler bank tube from a $77 \times 2 \mathrm{MW}$ coal based thermal power plant in the northwest region of India. Engineering Failure Analysis, vol. 26, p. 325-331, D0I:10.1016/J.engfailanal.2012.04.013.

[21] Hanke, N. (2012). Evaluation of a failed water wall boiler tube. Journal of Failure Analysis and Prevention, vol. 12, no. 1, p. 11-15, D0I:10.1007/s11668-011-9522-4.

[22] Abbasfard, H., Ghanbari, M., Ghasemi, A., Ghader, S., Rafsanjani, H.H., Moradi, A. (2012). Failure analysis and modelling of super heater tubes of a waste heat boiler thermally coupled in ammonia oxidation reactor. Engineering Failure Analysis, vol. 26, p. 285-292, D0l:10.1016/j. engfailanal.2012.06.012.

[23] Othman, H., Purbolaksono, J., Ahmad, B. (2009). Failure investigation on deformed superheater tubes. Engineering Failure Analysis, vol. 16, no. 1, p. 329-339, D0l:10.1016/j. engfailanal.2008.05.023.

[24] Purbolaksono, J., Ahmad, J., Beng, L. C., Rashid, A.Z., Khinani, A., Ali, A.A. (2010). Failure analysis on a primary superheater tube of a power plant. Engineering Failure Analysis, vol. 17, no. 1, p. 158-167, D0l:10.1016/j.engfailanal.2009.04.017.

[25] Botha, M., Hindley, M. P. (2015). One-way fluid structure interaction modelling methodology for boiler tube fatigue failure. Engineering Failure Analysis, vol. 48, p. 1-10, D0l:10.1016/j.engfailanal.2014.10.012.

[26] Ahmad, J., Purbolaksono, J., Beng, L.C., Rashid, A.Z., Khinani, A., Ali, A.A. (2009). Failure investigation on rear water wall tube of boiler. Engineering Failure Analysis, vol.16, no. 7, p.2325-2332, DOI:10.1016/j.engfailanal.2009.03.012.

[27] Begum, S., Karim, A.N.M., Zamani, A.S.M., Shafii, M.A. (2013). Wall thinning and creep damage analysis in boiler tube and optimization of operating conditions. Journal of Mechatronics, vol. 1, p. 1-6.

[28] Kumar, A., Sapra, P.K. (2013). Boiler tubes failure: Causes and remedies a case study of a fertilizer plant. International Journal on Emerging Technologies,vol. 4, no. 2, p. 132-135.

[29] Luo, X., Zhang, Z. (2013). Leakage failure analysis in a power plant boiler. IERI Procedia, vol. 5, p. 107-111, D0I:10.1016/j. ieri.2013.11.078.

[30] Haase, R. J., Hanke, L. D. (2013). Boiler stack economizer tube failure. Journal of Failure Analysis and Prevention, vol. 13, no. 5, p. 513-520, D0l:10.1007/s11668-013-9717-y.

[31] Šeruga, D., Fajdiga, M., Nagode, M. (2011). Creep damage calculation for thermo mechanical fatigue. Strojniški vestnik - 
Journal of Mechanical Engineering, vol. 57, no. 5, p. 371-378, DOl:10.5545/sv-jme.2010.108

[32] Saha, A., Shukla, A.K. (2014). Failure of a secondary superheater tube in a 140-MW thermal power plant. Journal of Failure Analysis and Prevention, vol. 14, no. 1, p. 10-12, DOl:10.1007/s11668-013-9773-3.

[33] Shokouhmand, H., Ghadimi,B., Espanani, R. (2015). Failure analysis and retrofitting of superheater tubes in utility boiler. Engineering Failure Analysis, vol. 50, p. 20-28, D0l:10.1016/j. engfailanal.2015.01.003.

[34] Movahedi-Rad, A., Plasseyed, S.S., Attarian, M. (2015). Failure analysis of superheater tube. Engineering Failure Analysis, vol. 48, p. 94-104, D0l:10.1016/j.engfailanal.2014.11.012.

[35] Saha, A., Roy, H., Shukla, A.K. (2015). Failure investigation of a final super heater tube in a $140 \mathrm{MW}$ thermal power plant. Journal of Failure Analysis and Prevention, vol. 15, no. 2, p. 184-189, DOI:10.1007/s11668-015-9928-5.

[36] Hu, Z.F., He, D.H., Wu, X.M. (2014). Failure analysis of T12 boiler re-heater tubes during short-term service. Journal of
Failure Analysis and Prevention, vol. 14, no.5, p.637-644, DOI:10.1007/s11668-014-9859-6.

[37] Javidi, M., Nematollahi, M. R., Lalehparvar, M.M., Ghassemi, A. (2016). Failure analysis of AISI 321 austenitic stainless steel water piping in a power plant. Journal of Failure Analysis and Prevention, vol. 16, no. 2, p. 209-215, Dol:10.1007/s11668016-0070-9.

[38] Liang, Z., Jin, X., Zhao, Q.(2014). Investigation of overheating of the final super-heater in a $660 \mathrm{MW}$ power plant. Engineering Failure Analysis, vol. 45, p. 59-64, D0l:10.1016/j. engfailanal.2014.06.022.

[39] Bettge, D., Klinger, C., Klingbeil, D., Eberle, A. (2014). Investigations on the breakdown of a heat recovery steam generator during the initial operation run. Engineering Failure Analysis, vol. 43, p. 253-270, D0l:10.1016/j. engfailanal.2013.12.005.

[40] Duda, P., Felkowski, L., Dobrzański, J. (2015). An analysis of an incident during the renovation work of a power boiler superheater. Engineering Failure Analysis, vol. 57, p. 248-253, DOI:10.1016/j.engfailanal.2015.07.011. 